\title{
Incentives and barriers for R\&D-based SMEs to participate in European research programs: An empirical assessment for the Netherlands
}

\author{
Jan Faber*, Jaco van Dijk and Frank van Rijnsoever \\ Innovation Studies, Copernicus Institute of Sustainable Development, Utrecht University, P.0. Box 80115, 3508 TC \\ Utrecht, The Netherlands
}

* Corresponding author. Email: J.Faber1@uu.nl

\begin{abstract}
As participation by small and medium-sized enterprises (SMEs) in European collaboration research programs is less than has been striven for, this study investigates the motives of R\&D-based SMEs for (non)participation in these programs. Based on the resource-based view, we formulate a set of hypotheses about incentives and barriers that influence the likelihood of participation by SMEs. These hypotheses are empirically tested using a survey of 247 Dutch R\&D-based SMEs. We find that European collaborative research programs attract the participation of rather limited numbers of especially science-based SMEs having prior experience with international collaboration, based on the incentives of cost sharing and knowledge sharing and the barrier formed by the costs of participating in these programs. Policy measures are derived that might improve the participation of SMEs in European collaborative research programs are derived from our results.

Key words: small and medium-sized enterprises; international cooperation; EU research programs; incentives; barriers; innovation policy.
\end{abstract}

\section{Introduction}

In a rapidly changing global economy, innovation is of central importance to the competitiveness of the EU (European Commission 2010). To support innovation in the EU, large-scale publicly funded EU research programs have been set up to strengthen the EU's scientific and technological knowledge production by financially stimulating international $\mathrm{R} \& \mathrm{D}$ cooperation between enterprises and research organizations (CORDIS 2007). The first editions of the EUREKA program and the Framework Program for Research and Technology Development (FP1) were implemented in the mid1980s, initially with a technology and industry development perspective, respectively, and followed up by later editions until today. Such research programs have the potential to produce significant entrepreneurial opportunities. In this respect, Audretsch and Keilbach (2007: 1249) state:

Contexts rich in knowledge should generate more entrepreneurship, reflecting more extensive entrepreneurial opportunities. By contrast, contexts impoverished in knowledge should generate less entrepreneurship, reflecting less extensive entrepreneurial opportunities.

A recent study by Barajas et al. (2012) indeed supports the added value of these programs for the technological capacity of firms and their productivity. Furthermore, these programs have greatly contributed to the build-up of international R\&D networks (Protogerou et al. 2013) that contain valuable social capital, give direction to the development of future innovations (Van Rijnsoever et al. 2014), and add to technological diversity (Van Rijnsoever et al. 2015).

However, the participation of industrial organizations and especially of small and medium-sized enterprises (SMEs) in the FP5 program (1998-2002) dropped by more than 50\% in the FP6 program (2002-6) and has not improved in the FP7 program (2007-13) (Technopolis 2009; AgentschapNL 2012). Therefore, since 2005 more specific attention has been paid to the participation of R\&Dbased SMEs in EU research programs, which serve:

.. as a key conduit for the spill-over of knowledge. (Audretsch et al. 2009: 39)

SMEs are conceived as more innovative and adaptive than large firms and are quicker in terms of time to market (Knight 2001). Furthermore, Van Praag and Versloot (2007) demonstrate that entrepreneurial firms obtain relatively higher levels of commercialization than their larger counterparts. Accordingly, participation in $\mathrm{EU}$ research programs by sufficient R\&D-based SMEs is perceived to be beneficial in terms of improving the EU's ability to commercialize innovations. To support the participation of $R \& D$-based SMEs in EU research programs, the Eurostars Program (EP; €1.14 
billion) has been implemented within the EUREKA program in 2005 (EUREKA 2013) and the Competitiveness and Innovation Framework Program (CIP; €3.62 billion) was started in 2007 (European Commission 2014a). CIP tries to stimulate SMEs to improve themselves in particular advanced technological fields, whereas EP tries to stimulate them to participate in international research collaborations with enterprises and research organizations. Furthermore, the European Commission set a desired target of $15 \%$ of the total budget of the FP7 program to be received by SMEs (FP7; 2007-13; €50.5 billion) (European Commission 2007, 2012). However, this target has still not been reached. On average, in 2011 SMEs in the EU received $13.6 \%$ of the total FP7 funding and Dutch SMEs only $12 \%$ ( $75 \%$ of the intended $15 \%$ ) (AgentschapNL 2012). This lagging participation of R\&D-based SMEs in the FP7 program and other EU research programs not only reduces the capability available for commercializing the knowledge produced ${ }^{1}$ but also further strengthens the dominance of participating research organizations in determining the topics of joint research projects. As many of those research organizations may have a preference for basic science instead of applied science, the risk increases that less opportunities for commercialization of the new knowledge that is produced become available for R\&D-based SMEs (Protogerou et al. 2010). Both effects of a lagging participation of R\&D-based SMEs in EU research programs, namely less capability and opportunities for commercializing the new knowledge that is produced, diminish the EU's ability to improve the competitiveness of its economy. Thus, it is important to obtain more insights into the factors that determine the participation of R\&D-based SMEs in EU research programs.

Several studies have addressed the potential barriers and incentives that prevent and/or stimulate SMEs to pursue international R\&D collaboration activities within research consortia and joint research ventures (Hagedoorn et al. 2000; Caloghirou et al. 2004). But only a few studies have explicitly addressed the participation of enterprises in publicly funded EU research programs (Barajas and Huergo 2010; Protogerou et al. 2010; Gilmore et al. 2013; Bach et al. 2014). No studies explicitly address both the barriers and incentives, which together influence SMEs' decisions to participate in the EU research programs. According to Barajas and Huergo (2010), no accepted model exists that explains the various factors which might influence the process of international R\&D collaboration. This also applies to international $\mathrm{R} \& \mathrm{D}$ collaboration within public research programs. This study aims to contribute to this topic by studying the association of potential incentives and barriers with the participation of SMEs in EU programs.

The incentives for, and barriers to, SME participation in EU collaborative research programs are derived from the resource-based view (RBV) of the firm (Wernerfelt 1984; Das and Teng 2000; Mahony and Pandian 1992) and their influences on SME participation in EU research programs are empirically assessed by means of a linear structural equations model. This so-called structural equations model (SEM) model contains a confirmatory factor analysis model in order to measure incentives which are not directly observed and barriers on multiple indicators, and to estimate a structural equation model (i.e. a regression equation) specifying the effects of the various incentives and barriers discerned on the dependent variable indicating the (non)participation of SMEs in the FP7-CP or EP programs based on a sample of Dutch R\&D-based SMEs. In this study we focus on the subprogram Cooperations of the FP7 program (FP7-CP; $€ 32.41$ billion) and the EP program as these programs explicitly stimulate international R\&D collaborations of enterprises and research organizations in which SMEs participate (prominently) in order to provide them with the knowledge spillovers necessary for developing new products, processes or services.

Theoretically, this study contributes to the RBV of the firm by demonstrating its ability to explain international collaboration of SMEs in public innovation programs like FP7-CP and Eurostars. The existing literature on SMEs' inter-firm collaboration focused strongly on the acquisition of complementary assets and capabilities (Kogut 1988; Narula and Hagedoorn 1999; Hagedoorn et al. 2000; Das and Teng 2000). In this paper we provide support for the finding of Bach et al. (2014), that joint knowledge production for future innovations via knowledge sharing is a much stronger incentive for them to participate in such projects. However, the results also demonstrate that there is an even stronger incentive for SMEs to participate in such projects induced by the short-term benefits that are expected and the costs of participating in a FP7-CP or EP project. Policy-makers may use the results of this study to improve the access of SMEs to international programs, such as the EU Horizon 2020 program that is currently being implemented (European Commission 2013). This program has a budget over $€ 70$ billion for the period 2014-20, and also focuses on innovation by SMEs.

The remainder of this paper is structured as follows. The theoretical foundations of this study and the hypotheses derived from them are presented in Section 2. Section 3 describes the methods of data collection, measurement and analysis that are applied. The results obtained are presented in Section 4. Finally, the conclusions derived from these results and their theoretical and policy implications and their limitations are discussed in Section 5.

\section{Theoretical framework}

When seeking public funds to finance innovation Dutch R\&D-based SMEs may choose to participate in EU programs. In such a decision, various incentives and barriers are weighed against each other. These incentives and barriers resemble, respectively, the expected advantages and disadvantages to be obtained by a SME. In Sections 2.1 and 2.2 we formulate hypotheses about incentives for, and barriers to, SMEs participating in EU collaborative research programs. These hypotheses form a model that explains the international collaboration of SMEs within these programs. This model is tested on a sample of Dutch R\&D-based SMEs in order to obtain empirical verification of the model for the decision for (non)participation in international publicly funded research.

SMEs are limited in terms of their resources and have limited possibilities for in-house development of knowledge and technology. In order to be able to develop exploitable innovations, an SME may seek to enter research partnerships to acquire access to the resources necessary for innovation (Kogut 1988; Narula and Hagedoorn 1999; Zahra et al. 2009; Nieto and Santamaria 2010; Brouthers et al. 2014). The reasons why firms try to gain access to valuable resources via research partnerships can be explained through the RBV of the firm (Das and Teng 2000). The idea underlying this view is that a firm's unique resources help to create its competitive advantage (Penrose 1959; Wernerfelt 1984). Resources are defined by Eisenhardt and Martin (2000: 1106) as:

... physical, human and organizational assets that can be used to implement value-creating strategies.

These resources can be both tangible and intangible in nature. As firms are heterogeneous in terms of their resource endowment, a competitive advantage may be achieved if a firm's resources are 
valuable, rare, difficult to imitate and non-substitutable (Barney 1991; Amit and Schoemaker 1993).

The RBV is applicable to our study since R\&D collaborations imply that resources are exchanged between partners (Powell et al. 1996; Ahuja 2000). Exchanging resources means that partners gain access to the resources they require and that they share resources and risks with others. Both receiving and sharing resources may form incentives for firms to collaborate in EU research programs (Bach et al. 2014).

Although the factors identified above can potentially induce SMEs to participate in collaborative EU research programs, a lack of resources can also form potential barriers for them to participation in such programs (Gilmore et al. 2013). Furthermore, we augment the RBV with the proximity framework by Boschma (2005), who discusses several types of proximity between partners that may either promote or hamper innovation. Thus, we recognize that not only resources do play a role in collaboration, but that the match between partners is also an influence (Ruef et al. 2003). Based on this combination, we identify a series of potential barriers to participation in international collaborations like those stimulated by EU programs. First, the incentives for SMEs to enter research partnerships imply that the SMEs are able to find suitable partner organizations in the EU and to collaborate effectively with them on topics predefined by the EU. These conditions for resource alignment among SMEs and their partner organizations are, however, not fulfilled a priori (Das and Teng 2000; Gilmore et al. 2013). Moreover, resource alignment is but one factor that can determine the decision to participate with others. Successful innovation requires that the partners have the right proximity on a number of dimensions. Boschma (2005) identifies five of these: cognitive, social, institutional, organizational, and geographical proximity. We consider three of these that are relevant to our study: the cognitive, social and cultural dimensions. The latter is a specific form of institutional proximity. Institutions are informally defined as:

\section{... the rules of the game. (North 1990)}

In our context it refers to how organizations differ in the way they organize things and how they coordinate their actions (see Boschma 2005). This can be through formal rules, but also through cultural norms and habits (Scott 1995; Boschma 2005). Since the formal rules of collaboration are strongly predetermined by the EU programs, we focus our attention on cultural norms and habits. We will label this form of institutional proximity as cultural proximity. Organizational proximity is about how the relations between partners are formalized, for example as a strategic alliance or a joint venture (Tidd and Bessant 2013). Since the EU programs strongly predefine how the collaborative relationships should be organized, this dimension is a constant for all SMEs. Therefore, we do not consider this dimension. Also, we do not consider geographical proximity, since this dimension is mostly about regional knowledge spillovers (Cooke et al. 1997; Ponds et al. 2007). Our study focuses on international collaboration. Therefore this dimension is not applied. Since we model these factors as barriers, we will define them in terms of distance instead of proximity.

Finally, public-private collaboration is not for free. Normally, there are costs associated with maintaining network ties (Burt, 2004), but gaining access to EU partners and their resources involves quite large additional investments of financial and human resources (Baragas and Huergo 2010; Gupta and Malhotra, 2013). Partnering problems, collaboration costs and administrative burdens may form barriers which prevent SMEs from entering EU research partnerships (Gilmore et al. 2013).

\subsection{Incentives}

Earlier studies have shown that to gain a competitive advantage it is of great importance that the resources that are accessed are complementary to the existing resource base (Kogut 1988; Narula and Hagedoorn 1999; Hagedoorn et al. 2000; Das and Teng 2000; Harrison et al. 1991, 2001). These resources need to be valuable, rare, inimitable and non-substitutable and are often intangible in nature (Newbert 2007). Complementary intangible resources allow firms to create new and unique opportunities and capabilities (Harrison et al. 2001). Gaining access to similar resources is more likely to lead to the formation of economies of scale for existing products. For innovation complementary resources are thus preferred over similar resources. Therefore, gaining access to complementary intangible resources in order to organize their value chain and exploit their unique resources in the short term may be an incentive for SMEs to participate in research partnerships like those stimulated by EU programs (Nieto and Santamaria 2010). The complementary intangible resources that SMEs seek to access by means of research partnerships with other organizations (i.e. research organizations and firms) are, particularly, specialized knowledge assets enabling R\&D as well as marketing capabilities enabling entrance to new markets (Teece 1986; Brouthers et al. 2014). At the same time, SMEs may also want to extend their organizational network via research partnerships in order to explore additional market opportunities for their unique resources (Adler and Kwon 2002). Accordingly, the following hypothesis is formulated.

H1: Access to complementary intangible resources is positively related to participation by SMEs in EU collaborative research programs.

In order to diminish the uncertainty of supply of complementary intangible resources, organizations collaborating in research partnerships may also jointly seek to develop new knowledge and innovation opportunities at a larger distance from their core competences for the long-term future (Murray et al. 2005; Bach et al. 2014). Such R\&D collaborations are based on the sharing of knowledge between partners. The downside of knowledge sharing is that the strategic value of the information for each firm decreases. However, in return the focal firm receives access to the knowledge from its partners, which can be used to develop new unique combinations (Burt 2004; Van Rijnsoever et al. 2015). This allows an SME to further strengthen its knowledge base, which makes it an attractive partner for future business opportunities (Van Rijnsoever et al. 2014). Sharing knowledge can thus strengthen an SME's competitive position (Spencer 2003). Indeed, innovation research has shown that firms that share knowledge with others have a higher innovative performance (Powell et al. 1996; Ahuja 2000; Spencer 2003). EU collaborative research programs have an extra added value with regard to knowledge sharing, because the pool of knowledge is larger and more diverse than with national programs, which greatly enlarges the potential number of new combinations to be made. Furthermore, sharing knowledge with firms that are active in other countries implies a lower potential loss of strategic value than sharing the knowledge with firms that are competitors on the domestic market. Knowledge sharing may thus serve as an incentive for SMEs to participate in EU collaborative research programs. These considerations lead to the following hypothesis. 
$\mathrm{H} 2$ : Knowledge sharing is positively related to participation by SMEs in EU collaborative research programs.

In many sectors the development of new innovations has become too costly and too uncertain to be carried out by a single firm (Powell et al. 1996), which is also the case for SMEs. Collaborating with strategic partners allows SMEs to share the costs that are involved. If a partnership is rewarded with R\&D subsidies, collaboration becomes even more attractive. Again, sharing the costs with a partner who is active in a foreign market can be more attractive than doing it with a direct competitor in the domestic market. Therefore, cost sharing can thus serve as an incentive for participating in EU public research programs.

H3: Cost sharing is positively related to participation by SMEs in EU collaborative research programs.

These incentives for SMEs to participate in EU collaborative research programs, namely gaining access to complementary intangible resources (knowledge, marketing capabilities, network extension) for short-term purposes, knowledge sharing for long-term purposes and cost sharing, are explicitly addressed and supported by these programs (Bach et al. 2014).

\subsection{Barriers}

Cognitive distance refers to the extent that knowledge bases overlap (Boschma 2005; Nooteboom et al. 2007), which determines the degree to which an SME is able to utilize accessed complementary resources and/or produced new knowledge from its partner organizations. If the difference in content and/or theoretical/analytical level between the knowledge bases of the SME and its partner organizations is too large, the SME is not able to absorb and utilize the accessed knowledge of its partners (Cohen and Levinthal 1990; Gilmore et al. 2013), which makes participation in an R\&D project less attractive. A complicating factor with projects carried out within EU research programs is that their subjects have to fall within predefined research themes. This implies that if the subjects of those themes differ too much from the core knowledge base of an SME in terms of content or depth, the cognitive distance between the SME and its prospective partners becomes too large for effective learning from each other. Consequently, SMEs will feel less attracted to participate in an EU research program.

H4: Cognitive distance between EU research projects and SME practices is negatively related to participation by SMEs in EU collaborative research programs.

The feature that distinguishes participation in EU research programs from many other research programs is that the collaborations are international in nature. SMEs have to find partner organizations abroad. The degree to which SMEs are able to find suitable partner organizations is strongly dependent on their relational and structural embedment in existing collaboration networks (Gulati 1995a,b). The degree to which a SME is socially embedded in a larger network is called social proximity (Boschma 2005); social distance is thus the degree to which the SME is not embedded. However, as SMEs are small in size and often not regularly involved in international collaborations, they often suffer from the liability of smallness (Narula 2004; Stinchcombe 1965) as well as the liability of unconnectedness (Powell et al. 1996), which means that they have a large social distance to potential international partners. And even if they collaborate within EU R\&D networks, they only take marginal positions at the fringes of the network (Protogerou et al. 2010). This implies that SMEs can experience severe difficulties with engaging in collaborative relationships with attractive partner organizations, which have more central positions in the EU R\&D networks. This large social distance between SMEs and attractive partner organizations in terms of network positions may discourage them from participating in these programs.

H5: Social distance between SMEs and potential attractive foreign partners is negatively related to participation by SMEs in EU collaborative research programs.

Based on the definition provided by Boschma (2005), cultural distance is the extent to which organizations differ in their cultural norms and habits. If SMEs are able to find suitable foreign partner organizations for participation in EU research programs, there is the risk that cultural differences in norms and habits disrupt the collaboration process (Hennart and Zeng 2002). Because of the duration of socialization, organizational cultures (Schein 1990) are rooted in national cultures (Hofstede et al. 1990). National cultural practices (i.e. language and habits), are the primary lens through which foreign partner organizations are evaluated by SMEs. Differences in national culture may hamper partners in effectively interacting to utilize their complimentary resources (Sirmon and Lane 2004). Accordingly, differences in national culture (i.e. cultural distance), evoke perceptions of differences in organizational culture that pose a risk to the innovation process and may discourage SMEs from participating in EU research programs.

H6: Cultural distance between SMEs and their potential foreign partners is negatively related to participation by SMEs in EU collaborative research programs.

Next to these cognitive, social and cultural barriers discouraging SMEs from participating in EU research programs, there are two more barriers that might reduce the likelihood of their participation in these programs. Despite the benefits of cost sharing (including receiving subsidies), participation in EU research programs still triggers considerable additional investments by SMEs (especially in terms of money but also time and expert manpower). As most SMEs only have limited resources (Narula 2004) and experience considerable difficulties with attracting external finance (Gilmore et al. 2013), the perceived participation costs may discourage them from participating in EU research programs.

H7: Participation costs are negatively related to SME participation in EU collaborative research programs.

Furthermore, in order to be selected for an EU research program, SMEs and their partner organizations must go through complex and long-lasting application procedures, which place a heavy administrative burden on each of the SMEs involved (Baragas and Huergo 2010). The complexity and duration of the application procedures to be completed for entering EU research programs may discourage SMEs from participating in those programs (Gilmore et al. 2013).

H8: Complexity and duration of the EU application procedures are negatively related to participation by SMEs in EU collaborative research programs.

\section{Methods}

\subsection{Data collection}

The tests of the hypotheses are based on data collected for a sample of Dutch R\&D-based SMEs having less than 250 employees and 
capable of independent decision-making (i.e. not being a subsidiary of another firm or a member of a holding). These SMEs have been selected as the EU collaborative research programs are only interesting for them. SMEs not undertaking R\&D are not equipped to participate in these programs. The sample of Dutch R\&D-based SMEs was drawn in October 2009 from the set of Dutch SMEs registered by the Dutch Ministry of Economic Affairs, which at that time received tax reductions on actively performing $R \& D .^{2}$ Two groups of SMEs have been derived from this registration, namely SMEs that do participate in either the EP or FP7-CP program or both, and SMEs that do not participate in these programs or any other EU research program. The first group consists of 479 SMEs. ${ }^{3}$ The second group consists of 14,366 SMEs. Because of the size of the latter group, a random sample (without replacement) of $10 \%$ was drawn from this group for administrative reasons. ${ }^{4}$ This resulted in a sample of 1,437 Dutch R\&D-based SMEs not participating in the EP and FP7-CP programs. All 479 SMEs that actually participated in either the EP or the FP7-CP program or both have been included in this study. This resulted in a total sample of 1,916 SMEs, who were invited to participate in a web-based survey developed by the authors (see Appendix 1). The sampling, invitation to participate in the survey, and collection of responses were carried out by the Ministry of Economic Affairs in order to ensure the non-disclosure of the names and addresses of individual firms. Eventually, a total of 247 SMEs returned a completed questionnaire: 197 SMEs from group $1(13.7 \%)$ and 50 SMEs from group $2(10.4 \%)$. The data collection procedures applied do, however, not allow us to assess the representation of the 1,916 SMEs in the original sample who do and do not participate in the FP7-CP and/or EP by the 247 responding SMEs. Therefore, the results derived from the collected data only hold for the responding firms and should be regarded as tentative and not as valid for all SMEs invited to cooperate in this study.

The choice to sample R\&D-based SMEs from the tax reduction database was made for two reasons. First, there is no official registration of R\&D-based SMEs within the Netherlands neither by the Dutch Chamber of Commerce nor elsewhere. Thus, the study misses out on R\&D-based SMEs not participating in the tax reduction scheme. Alternatively, a large sample of firms operating in industry categories prone to doing their own R\&D could have been drawn from the Dutch Chamber of Commerce database. But then the study would have missed out on R\&D-based SMEs operating in other industry categories. Furthermore, afterwards the responses of R\&Dbased SMEs should be separated from those obtained from large R\&D-based firms and non-R\&D-based SMEs and large firms, thereby tremendously reducing the response rate and admissible sample without knowing its representativeness. In order to avoid these problems, a huge sample of all firms registered at the Dutch Chamber of Commerce could have been drawn. But still the responses of R\&D-based SMEs should be separated afterwards from the other responses, thereby reducing the response rate and the admissible sample even more severely than before also without knowing their representativeness. So, a good registration of the population of Dutch R\&D-based SMEs focused on in this study is clearly missing.

Second, the values of the dependent concept of (non)participation in the EP and/or FP7-CP program for the SMEs in the sample are obtained from administrative sources and not provided by the participating SMEs themselves. This avoids measurement errors in those values, due to common method bias and other sources of erroneous answers (Podsakoff et al. 2003), and increases the construct validity of these values enormously and, subsequently, the internal and external validity of the results obtained (Riley1963). This argument weighted heavily in the choice to sample Dutch R\&D-based SMEs from the tax reduction database.

\subsection{Operationalization}

\subsubsection{Concepts}

Data on the dependent variable were known a priori for the sample of Dutch SMEs drawn from the tax reduction, FP7 and EP databases. The dependent variable was measured as a dichotomous variable reflecting each SME's participation in the FP7-CP and/or EP (1=yes; $0=$ no).

All but one of the independent concepts (i.e. incentives and barriers) have been measured on multiple indicators observed for each SME in the sample. All observable indicators of the unobserved constructs representing the independent concepts (including social distance) have been measured as ordinal variables on 5-point scales (1: not important-5: very important) (see Appendix 1). Access to complementary intangible resources has been measured on three indicators: gaining access to complementary knowledge, gaining access to new and larger markets, and extending the current network of contacts/relations. Sharing of firm-specific knowledge and intellectual property rights (IPR) has been measured on two indicators: sharing firm-specific knowledge and sharing IPR. Sharing costs of $R \mho D$ and product development has been measured on two indicators: sharing costs of conducting fundamental research and sharing costs of developing new products/services. Cognitive distance has been measured on two indicators: distance in subjects between the themes in the FP7-CP and EP and daily practice of the SME and distance in theoretical level between the themes in the FP7-CP and EP and daily practice of the SME. Social distance to potential foreign partner organizations has been measured on only one indicator: difficulties with finding suitable foreign partners. Cultural distance has been measured on two indicators: unfamiliarity with the language of potential foreign partners and differences in habits. Complexity and duration of the application procedure has been measured on two indicators: the complexity of the application procedure and the length of the application procedure. Costs of participation have been measured on three indicators: the time, employees and finances needed for participation.

\subsubsection{Control variables}

It may be assumed that the different incentives and barriers are not experienced equally by all SMEs (Lloyd-Reason and Mughan 2008). Thus, assessing the influence of the differences in incentives and barriers on the decisions of SMEs to participate in European research programs requires controlling for factors other than the incentives and barriers that have already been mentioned that might influence their decision. All control variables have been measured using single indicators.

First, a certain 'critical mass' in terms of resources and experience is required for conducting R\&D activities in general and to be able to participate in the often complex and long-lasting projects of, for example, FP7 (Barajas and Huergo 2010). Therefore, the size of the SMEs is taken into account since larger SMEs can be conceived to have acquired a larger 'critical mass'. Size is measured as an ordinal variable with three different size categories in terms of number of employees as proposed in the European SME definition (European Commission 2009) (1=1-10 employees, $2=11-50$ employees, $3=51-250$ employees). 
Second, the age of the SME is also taken into account in order to represent its accumulated experience in general. Age is measured as the number of years of existence of an SME (years).

Third, besides age and size, prior experience with international activities can be said to change the perception of incentives and barriers (Keogh and Evans 1999). Prior experience with international $\mathrm{R} \& \mathrm{D}$ cooperation in EU research programs has stimulated firms to conduct these activities again (Barajas and Huergo 2010). SMEs with international experience will more easily find partners and are better able to manage the process associated with international cooperation. Prior international experience is represented by four different types of activities conducted by SMEs in the past three years: import, export, international collaboration, and other international activities. All four types of international activities help SMEs to become acquainted with cooperation with foreign partner organizations, both vertically (through import and export) and/or horizontally in the value chain (through lateral collaboration and other activities). These four types of international activities have been distinguished in order to find out whether only previous international bilateral or multilateral collaborations (within or outside of EU research programs) stimulates SME participation in EU research partnerships or other types of previous international cooperation stimulate SME participation in EU research partnerships. The four types of prior international experience are measured as dummy variables $(1=$ yes, $0=$ no).

Finally, programs such as FP7 are structured according to different themes and aim to strengthen the European position in terms of these themes. SMEs operating within particular industries that do not relate to these themes can thus be assumed to be less likely to participate. Accordingly, there may be an industry effect. Industry is measured by four dummy variables representing Pavitt's industry classification of science-based, special supplier, scale-intensive and supplier-dominated firms (Pavitt 1984), which is based on the Dutch industry classification (SBI) codes. The Dutch SBI coding is identical to the European NACE rev.1.1 industrial classification (Centraal Bureau voor de Statistiek 2010; Fifo Ost 2010). The original SBI classification and the Pavitt classification derived from it can be found in Appendix 2. Pavitt's industry classification is used in this study as it is strongly based on the internal and external sources of knowledge and technologies of firms used by them for the development of innovations. So, Pavitt's industry classification acknowledges the RBV-based notion that firms need to develop and use their unique resources to be complemented with additional necessary resources from external organizations via horizontal and/or vertical collaborative relationships in order to innovate.

\subsection{Analysis}

Values of the factor loadings of the unobserved constructs on their observable indicators were obtained using factor analyses. First, an exploratory factor analysis was conducted. The unidimensionality of each unobserved construct specified should be confirmed by the Kaiser criterion applied (eigenvalue $>1.0$ ) and the estimated pattern of factor loadings of each latent construct on the indicators of all latent constructs (by means of the maximum likelihood (ML) method with oblique rotation of the unobserved constructs) (Tabachnik and Fidell 2007). Next, the solution obtained from the exploratory factor analysis was specified in a confirmatory factor analysis model in which the unobserved constructs identified have been measured on specific sets of these indicators. The confirmatory factor analysis model has been estimated as part of an SEM which also contains the regression equation specifying the structural effects of the independent concepts of incentives and barriers formulated in $\mathrm{H} 1-\mathrm{H} 9$ as well as of the control variables on the dependent variable of (non)participation in the EP and/or FP7-CP programs (Jöreskog and Sörbom 1993). The control variables and the independent concept social distance have been measured in the SEM on single observable indicators of their presence for each SME in the sample. The observable indicators have been measured on dichotomous, ordinal, and ratio scales.

In order to estimate the specified structural effects of the control variables and independent concepts on the dependent variable and the factor loadings of the independent concepts on their multiple indicators simultaneously, all effects have been specified in one SEM model. This model is estimated by means of the ML method based on the input correlation matrix of all observed indicators (Jöreskog and Sörbom 1993), which can be found in Appendix 3. This correlation matrix contains polychoric correlations for pairs of categorical (= dichotomous/ordinal) variables (Olsson 1979), polyserial correlations for pairs of categorical and continuous variables (Olsson et al. 1982), and Pearson correlations for pairs of continuous variables. Polychoric and polyserial correlations are ML estimates of the Pearson correlation of the unobserved, normally distributed, standardized continuous variable underlying each categorical variable (being its observable dichotomous or ordinal realization) and another categorical or continuous variable, respectively. The fit of the SEM model to the input correlation matrix is indicated by three measures of fit: the goodness of fit indicator $(0 \leq \mathrm{GFI} \leq 1)$, the adjusted goodness of fit indicator $(0 \leq \mathrm{AGFI} \leq 1)$, and the root mean squared error of approximation $(0 \leq \mathrm{RMSEA} \leq 1)$. GFI, AGFI $>0.90$, and RMSEA $<0.05$ indicate an acceptable fit of the SEM model to the input correlation matrix (Jöreskog and Sörbom 1993).

\section{Results}

The estimated means and standard deviations of all observed variables and their polychoric, polyserial or Pearson correlations are presented in Appendix $3(\mathrm{~N}=247)$. As can be seen, there is no serious multicollinearity ( $r<0.90$; O'Brien 2007) among the independent concepts and control variables except between the Pavitt categories of industries, which is inherent to this mutually exclusive classification. The correlations have been placed in the input matrix used to derive ML estimates of the factor loadings and regression coefficients specified in the integrated SEM model by means of the LISREL $^{\text {TM }}$ computer program (Jöreskog and Sörbom 1993).

The ML estimates of the factor loadings of the unobserved independent concepts (incentives and barriers) in the exploratory factor analysis model and the confirmatory factor analysis model (as a part of the entire SEM model; all with $\mathrm{p}<0.001$ ) are presented in Table 1. The estimates of the factor loadings in this confirmatory factor analysis model (for measurement of the unobserved constructs) are compared with the ML estimates of the factor loadings of the factors (with an eigenvalue $>1.0$ ) resulting from the exploratory factor analysis of the same observed indicators that was carried out before. This has been done in order to check whether or not the specification of the confirmatory factor analysis model of the incentives and barriers specified and the estimates of their factor loadings are an artifact of the collected data on Dutch R\&D-based SMEs. Exploratory factor analysis of the set of observed indicators resulted in seven factors with an eigenvalue $>1.0$ and an estimated pattern 
Table 1. ML factor loading matrices after oblique rotation from exploratory and confirmatory factor analyses of multiple observed indicators of incentives and barriers $(\mathrm{N}=247)$

\begin{tabular}{|c|c|c|c|c|c|c|c|}
\hline \multirow{2}{*}{$\begin{array}{l}\text { Observed indicators (Section } \\
3.2 \text { and Appendix 1) }\end{array}$} & \multicolumn{7}{|c|}{ Exploratory factor/confirmatory factor (name) } \\
\hline & $\begin{array}{l}\text { Access to complementary } \\
\text { intangible resources }\end{array}$ & $\begin{array}{l}\text { Knowledge } \\
\text { sharing }\end{array}$ & Cost sharing & $\begin{array}{l}\text { Cognitive } \\
\text { distance }\end{array}$ & $\begin{array}{l}\text { Cultural } \\
\text { distance }\end{array}$ & $\begin{array}{l}\text { Application } \\
\text { procedure }\end{array}$ & Participation cost \\
\hline $\begin{array}{l}\text { Access complementary } \\
\text { knowledge }\end{array}$ & $0.585 / 0.679$ & $0.067 / 0.000$ & $0.373 / 0.000$ & $0.026 / 0.000$ & $-0.121 / 0.000$ & $0.000 / 0.000$ & $0.227 / 0.000$ \\
\hline $\begin{array}{l}\text { Extending organization } \\
\text { network }\end{array}$ & $0.955 / 0.898$ & $0.068 / 0.000$ & $0.226 / 0.000$ & $0.113 / 0.000$ & $-0.227 / 0.000$ & $0.082 / 0.000$ & $0.014 / 0.000$ \\
\hline Access new markets & $0.709 / 0.640$ & $0.099 / 0.000$ & $0.137 / 0.000$ & $0.167 / 0.000$ & $0.035 / 0.000$ & $0.028 / 0.000$ & $0.067 / 0.000$ \\
\hline Cost sharing R\&D & $0.32 / 0.000$ & $0.000 / 0.000$ & $0.992 / 0.976$ & $0.011 / 0.000$ & $-0.107 / 0.000$ & $0.128 / 0.000$ & $0.257 / 0.000$ \\
\hline $\begin{array}{l}\text { Cost sharing new product } \\
\text { development }\end{array}$ & $0.238 / 0.000$ & $-0.001 / 0.000$ & $0.906 / 0.911$ & $0.188 / 0.000$ & $-0.035 / 0.000$ & $0.112 / 0.000$ & $0.305 / 0.000$ \\
\hline Knowledge sharing & $0.086 / 0.000$ & $0.991 / 0.864$ & $-0.087 / 0.000$ & $0.277 / 0.000$ & $0.090 / 0.000$ & $-0.115 / 0.000$ & $0.065 / 0.000$ \\
\hline IPR sharing & $0.104 / 0.000$ & $0.730 / 0.813$ & $0.115 / 0.000$ & $0.305 / 0.000$ & $0.055 / 0.000$ & $-0.121 / 0.000$ & $0.255 / 0.000$ \\
\hline $\begin{array}{l}\text { Time needed for } \\
\text { participation }\end{array}$ & $0.019 / 0.000$ & $0.152 / 0.000$ & $0.140 / 0.000$ & $0.250 / 0.000$ & $0.074 / 0.000$ & $0.382 / 0.000$ & $0.838 / 0.850$ \\
\hline $\begin{array}{l}\text { Personnel needed for } \\
\text { participation }\end{array}$ & $0.054 / 0.000$ & $0.221 / 0.000$ & $0.190 / 0.000$ & $0.256 / 0.000$ & $0.094 / 0.000$ & $0.194 / 0.000$ & $0.881 / 0.823$ \\
\hline $\begin{array}{l}\text { Finances needed for } \\
\text { participation }\end{array}$ & $0.185 / 0.000$ & $0.03 / 0.000$ & $0.339 / 0.000$ & $0.169 / 0.000$ & $0.045 / 0.000$ & $0.100 / 0.000$ & $0.520 / 0.536$ \\
\hline Complexity of application & $0.052 / 0.000$ & $-0.115 / 0.000$ & $0.103 / 0.000$ & $0.139 / 0.000$ & $-0.056 / 0.000$ & $0.964 / 0.889$ & $0.241 / 0.000$ \\
\hline Duration of application & $0.076 / 0.000$ & $-0.125 / 0.000$ & $0.152 / 0.000$ & $0.108 / 0.000$ & $-0.052 / 0.000$ & $0.854 / 0.927$ & $0.291 / 0.000$ \\
\hline Difference in subjects & $0.096 / 0.000$ & $0.199 / 0.000$ & $0.130 / 0.000$ & $0.488 / 0.552$ & $0.058 / 0.000$ & $0.087 / 0.000$ & $0.203 / 0.000$ \\
\hline Difference in theoretical level & $0.127 / 0.000$ & $0.287 / 0.000$ & $0.009 / 0.000$ & $0.995 / 0.861$ & $0.091 / 0.000$ & 0.099/0.000 & $0.199 / 0.000$ \\
\hline Differences in language & $0.112 / 0.000$ & $0.079 / 0.000$ & $-0.090 / 0.000$ & $0.092 / 0.000$ & $0.999 / 0.975$ & $-0.055 / 0.000$ & $0.066 / 0.000$ \\
\hline Differences in habits & $-0.083 / 0.000$ & $0.062 / 0.000$ & $-0.032 / 0.000$ & $0.097 / 0.000$ & $0.819 / 0.839$ & $-0.047 / 0.000$ & $0.089 / 0.000$ \\
\hline
\end{tabular}

of factor loadings that is almost identical to the estimated a priori specified pattern of factor loadings in the confirmatory factor analysis model. From these results it can be concluded that the confirmatory factor analysis model of the seven unobserved incentives and barriers derived previously is correctly specified.

Table 2 presents the ML estimates of the standardized regression coefficients, representing the structural effects of: first, only the control variables; and second, the control variables and the independent concepts on Dutch SMEs' participation in the EP and FP7$\mathrm{CP}$ programs. The $\mathrm{R}^{2}$ value increases from 0.588 to 0.761 by adding the independent concepts to the model. So, the complete Model (2) predicts the variance in (non)participation of Dutch SMEs in the EP and FP7-CP programs for $76 \%$. As Model (1) is an regression equation (based on polychoric, polyserial, and Pearson correlations) with fixed correlations of the independent control variables, the fit of the estimated regression equation to the input matrix is by definition perfect, as is indicated by the values of GFI, AGFI, and RMSEA (with $d f=0$ ). The entire SEM model, of which Model (2) is the part containing the structural effects of the (un)observed independent concepts (incentives and barriers) and control variables, also fits well to the input correlation matrix, as indicated by $\mathrm{GFI}=0.966, \quad \mathrm{AGFI}=0.931$, and $\mathrm{RMSEA}=0.039$ (with $d f=202$ ).

Of the incentives and barriers specified as independent concepts, only knowledge sharing and cost sharing for R\&D and product development and the costs of participation have statistically significant estimated effects on Dutch SMEs' participation in the EP and FP7$\mathrm{CP}$ programs. Of the control variables specified, the dummy variable representing prior international collaboration and the dummy variables representing specialized-supplier and supplier-dominated firms turn out to have statistically significant estimated effects on Dutch SMEs' participation in the EP and FP7-CP programs.
The results show, first, that SMEs are not driven by the incentive of gaining access to complementary intangible resources (i.e. knowledge, markets, and networks) in order to develop new innovations in the short term for themselves based on their unique resources, thereby disproving H1. Further, the results indicate that SMEs participate in both collaborative research programs for reasons of knowledge sharing and cost sharing for joint R\&D and (long-term) product development. This supports $\mathrm{H} 2$ and $\mathrm{H} 3$. The incentive of cost sharing is, however, felt more strongly by SMEs than the incentive of knowledge sharing $(0.374$ versus 0.229$)$ in relation to participation in EU research collaborations.

When looking at the barriers it can be observed that cognitive, social, and cultural distance have little influence on the decision of SMEs not to participate in EU research programs. The SMEs in our sample do not see the finding of, and collaboration with, partners from other countries on the right theme as a problem: this disconfirms H4-H6. Also the application procedure itself as a barrier (H7) does not exert a statistically significant effect. However, the results do indicate that SMEs do not participate in the EP and FP7-CP programs due to the costs of participation in terms of the money, expert manpower, and time involved. Thus, the hypothesized effect that the required investments in terms of time, money, and people act as a barrier to SMEs' participation in European research programs (H8) is supported.

Thus, it is not so much the problem of partnering and collaborating, or the complexity and/or duration of the application procedures that act as barriers for SMEs, but the required investments of money, expert manpower, and time necessary for participation in an EP or FP7-CP project. It seems that SMEs' resource constraints do limit their willingness to raise the investments for participating in EU collaborative research programs (with rather low chances of success (i.e.17-22\%); Senternovem 2009). The cost-sharing incentive 
Table 2. Estimated standardized structural effects $(N=247)$

\begin{tabular}{|c|c|c|c|}
\hline \multicolumn{2}{|c|}{$\begin{array}{l}\text { Dependent variable: Participation } \\
\text { in FP7-CP and/or EP }\end{array}$} & \multirow[t]{2}{*}{ Model (1) } & \multirow[t]{2}{*}{ Model (2) } \\
\hline \multicolumn{2}{|l|}{ Control variables: } & & \\
\hline \multirow{4}{*}{ Experience with: } & Imports & 0.192 & 0.482 \\
\hline & Exports & $-0.574 *$ & -0.934 \\
\hline & Prior international collaboration & $0.833 * * *$ & $0.898 * *$ \\
\hline & Alternative international contacts & 0.008 & -0.105 \\
\hline Age & & 0.143 & 0.113 \\
\hline Size & & -0.132 & -0.020 \\
\hline \multirow[t]{4}{*}{ Industry: } & Science-based & $0.101^{* *}$ & 0.054 \\
\hline & Scale-intensive & -0.018 & -0.068 \\
\hline & Specialized suppliers & $0.062 *$ & $0.144 *$ \\
\hline & Supplier-dominated & $-0.147 * * *$ & $-0.175 *$ \\
\hline \multicolumn{4}{|c|}{ Independent variables: } \\
\hline \multicolumn{2}{|c|}{$\begin{array}{l}\text { H1: Access to complementary } \\
\text { intangible resources }\end{array}$} & & 0.027 \\
\hline \multicolumn{2}{|c|}{ H2: Knowledge sharing } & & $0.229 * *$ \\
\hline \multicolumn{2}{|c|}{ H3: Cost sharing } & & $0.374 * *$ \\
\hline \multicolumn{2}{|c|}{ H4: Cognitive distance } & & -0.189 \\
\hline \multicolumn{2}{|c|}{ H5: Social distance } & & -0.166 \\
\hline \multicolumn{2}{|c|}{ H6: Cultural distance } & & 0.194 \\
\hline \multicolumn{2}{|c|}{$\mathrm{H} 7$ : Participation costs } & & $-0.277^{*}$ \\
\hline \multicolumn{2}{|c|}{$\begin{array}{l}\text { H8: Complexity and duration } \\
\text { of application procedures }\end{array}$} & & 0.089 \\
\hline \multicolumn{2}{|c|}{$\mathrm{R}^{2}$} & 0.588 & 0.761 \\
\hline \multicolumn{2}{|l|}{ GFI } & 1.000 & 0.966 \\
\hline \multicolumn{2}{|l|}{ AGFI } & 1.000 & 0.931 \\
\hline \multicolumn{2}{|c|}{ RMSEA } & 0.000 & 0.039 \\
\hline \multicolumn{2}{|c|}{ Degrees of freedom $(d f)$} & 0 & 202 \\
\hline
\end{tabular}

on the one hand and the costs-of-participation barrier on the other indicate that a financial trade-off is made by SMEs when deciding on participation in European collaborative research programs. While the possibility of sharing the costs of R\&D and product development is perceived as an incentive, a SME may not participate if the expected benefits from cost sharing do not compensate for the expected costs of participation. Thus, financial motives prevail over all other hypothesized motives.

Addressing the potential effects of prior international experience indicates that SMEs having prior experience with international collaboration are far more likely to participate in the EP and FP7-CP programs. SMEs that have previously managed international collaboration appear to have less fear about dealing with the process of participation in these programs than SMEs lacking such experience. The results indicate that this only holds for international collaboration, since prior experiences with imports, exports, or alternative international contacts do not have a significant effect. Apparently, international lateral collaboration is perceived as quite different from other forms of international activity. Another implication of these results may be that SMEs already collaborating in research partnerships based on knowledge sharing apply together with their partners for participation in the FP7-CP or EP simply for financial reasons.

In terms of controlling for industry effects, it is interesting to note the effect of the dummy variable representing membership of the science-based industry. While this dummy is statistically significant in Model (1) which only contains the control variables, adding the independent concepts eliminates this effect, whereas the effects of the other industry dummies do not change significantly.
This change of effects will be related to the specific R\&D capabilities of science-based SMEs, which better enable them to participate in the EP and FP7-CP programs aiming at the development of highlevel knowledge and technologies. Consequently, it seems that Dutch SMEs in science-based industries participate more in these programs than SMEs in other types of industries, for reasons related to the financial funding of their R\&D activities. This is understandable, since science-based SMEs are a primary target of the EU collaborative research programs. Furthermore, since science-based SMEs are better able to absorb the basic scientific knowledge produced than are other types of SMEs, they also benefit most from participating in these programs, which are dominated by public and private research organizations.

\section{Conclusions and discussion}

\subsection{Conclusions}

The decision of the SMEs who were investigated to participate in the EP and FP7-CP programs is primarily based on the long-term incentive of knowledge production for future innovations via knowledge sharing and the short-term trade-off made between the expected benefits of cost sharing (including obtaining EU subsidies) and the costs of resources involved in that participation, as well as on whether or not they already have experience with international collaboration. The incentive of gaining access to complementary intangible resources and the barriers raised by the perceived cognitive, social, and cultural distances, and the complexity and duration of the application procedure were not found to play an important role 
in the decisions made by SMEs to (non)participate in the EP and FP7-CP programs which were studied.

As the participation in European collaborative research programs is only one of the options that SMEs have to collaborate with other organizations on $\mathrm{R} \& \mathrm{D}$ via knowledge sharing in order to generate potential innovative concepts for the future, the decision of SMEs to do so is found to be also strongly dependent on the tradeoff they make between the expected benefits of cost sharing and the expected short-term costs of participation. As a result, the EP and FP7-CP programs attract the participation of rather limited numbers of especially science-based SMEs based on minimizing their transaction costs for performing joint $R \& D$ via knowledge sharing instead of gaining a competitive advantage with the joint development of actual innovations and thereby contributing to the development of high-tech industries within the EU.

\subsection{Theoretical implications}

The existing literature on SMEs' inter-firm collaboration based on contractual agreements has focused strongly on the acquisition of complementary assets and capabilities from a resource-based perspective (Kogut 1988; Narula and Hagedoorn 1999; Hagedoorn et al. 2000; Das and Teng 2000). The results of this study show, however, that this incentive plays an insignificant role as a motive for participation in publicly funded EU R\&D collaboration projects. Joint knowledge production for new innovations via knowledge sharing is a significant incentive for the Dutch SMEs in our sample to participate in such projects. But cost sharing of joint knowledge production and innovation is an even stronger incentive for them. Three explanations for these results, which are not mutually exclusive, will be given.

First, firms and research organizations cannot apply individually for participation in the EP and FP7-CP programs, they can only apply as a consortium. Accordingly, they will apply as a consortium after they have agreed upon the joint research to be carried out and the new knowledge to be generated based on knowledge sharing. At the same time, as the success of joint research is not guaranteed beforehand, they will consider at which price they have to deliver their research efforts and make a trade-off between the expected benefits of joint research in terms of cost sharing (including EU subsidies) and the expected costs of participating in joint research in terms of finances, expert manpower, and time to be invested. As the expected benefits of joint research are a necessary but not sufficient condition for generating new knowledge, cost sharing plays a more prominent role in Dutch SMEs' decisions regarding their participation in the publicly funded EP and FP7-CP programs than does knowledge sharing.

Second, the cost-sharing incentive (including EU subsidies) may have been a more easily attainable source of funding, because the EP and FP7-CP programs are focused on initiating research collaborations and their expected results as a prerequisite for innovation in the future instead of on the outcome like venture capitalists, namely producing profitable innovations in the short term (Cumming and Macintosh 2006; Schneider and Veugelers 2010).

Third, the significant effects of cost sharing, costs of participation and knowledge sharing found especially for science-based Dutch SMEs correspond with the finding of Muijrers and Faber (2012) that incentives like knowledge sharing and cost sharing stimulated Dutch biotech SMEs to start bilateral international research collaborations with foreign public research institutes, in particular. Dutch biotech SMEs started these international research collaborations when they already had products on the market, in order to diversify their portfolios of products.

Our results, and these three arguments, imply that Dutch R\&Dbased SMEs participate in the EP and FP7-CP programs in order to share the associated costs of research activities, the relatively easy attainable public EU funding compared to private funding, and knowledge sharing for joint new-knowledge production. But as the last reason, derived from the RBV, can also be realized in other forms of (international) R\&D collaboration, the choice of Dutch $\mathrm{R} \& \mathrm{D}$-based SMEs to participate in the EP and FP7-CP programs seems to be determined primarily by the immediate short-term transaction costs of doing joint research (Williamson 1981) and less by the long-term potential benefits of the prospective new knowledge produced. Accordingly, the participating SMEs seem more interested in low-cost extension of their knowledge base via the development of science-based knowledge for potential future use in innovations than in low-cost development of innovations to be commercialized in the short term. So, participation of SMEs in the EP and FP7-CP programs is not driven by RBV-based motives of developing current unique resources into profitable innovations in order to gain a shortterm competitive advantage, but by the RBV-based motives of gaining access to complementary knowledge via knowledge sharing in order to extend their knowledge base as a source for developing unique resources in the future. But their actual involvement in this type of knowledge sharing is strongly determined by Transaction Cost Theory related motives based on the short-term benefits of cost sharing and the short-term costs of participation in the various options of R\&D between 'make' (i.e. in-house R\&D) or 'buy' (i.e. outsourcing $R \& D$ ) in order to develop new knowledge for potential future innovations (Williamson 1981). Thus, the EP and FP7-CP programs are used by SMEs in the precompetitive R\&D phase which is prior to the phase of actually developing innovations. Both research programs explicitly stimulate the incentives for SMEs to participate in these programs for short-term as well as long-term purposes (Bach et al. 2014). The results of this study seriously question the objective of both EU research programs of supporting the competitiveness of the European economy by bringing more knowledge-based products to the market. Apparently, the gap between invention and innovation (Tidd and Bessant 2013) is not closed by SMEs participating in both EU research programs. Also, the gap had not previously been closed by them in the longer term (Barajas et al. 2012).

These insights seem to hold especially for science-based firms participating in the FP7-CP and EP programs, which is quite plausible (Protogerou et al. 2010). Research organizations play a prominent role in these EU research programs because of the scientific and technological excellence asked for. This implies that approved research projects tend to focus on basic science subjects. Furthermore, research organizations, especially public research organizations, are interested in publishing their results. So, because the new knowledge produced is prone to disclosure, science-based SMEs are most likely to participate in EU collaborative research programs just for the joint production of new basic knowledge from which they can derive new innovative concepts to be further developed by themselves (Luukkonen 2002). As basic science results are published and communicated internationally, this might also explain why science-based SMEs are barely vulnerable to the barriers to participation in the EP and FP7-CP programs induced by the cognitive, social, and cultural distances to their potential partners. They already know the subjects and potential partners from the articles published and the international conferences and other meetings attended. 
The results presented in this study on the incentives and barriers inducing R\&D-based SMEs to (non)participate in the EU EP and FP7-CP programs integrate some of the findings of Bach et al. (2014) on only the incentives for already participating firms to participate in the EU FP6 and FP5 programs (i.e. cost sharing and knowledge sharing) and of Gilmore et al. (2013) on only the barriers experienced by SMEs in general to participate in EU research programs (i.e. resource limitations). Other important incentives and barriers found by Bach et al. (2014) and Gilmore et al. (2013) only showed insignificant effects in this study (e.g. gaining access to complementary intangible resources, extending the organizational network, length and duration of the application process, irrelevance of program aims to SMEs' interests (cognitive distance) and difficulties with finding potential partners (social distance)). This may be deduced because this study has focused on R\&D-based SMEs. Our results apply especially to science-based SMEs, who seem to be more inclined to participate in the EP and FP7-CP programs than are other types of SMEs. Thus, science-based SMEs are also the most interesting for the EU to attract to participate in its collaborative research programs in order to support the long-term goal of the EU of becoming a knowledge-based economy.

\subsection{Policy implications}

The results of this study indicate three categories of potentially more targeted governmental stimulation of SMEs' participation in EU collaborative research programs. First, SMEs operating within specialized-supplier and especially science-based industries seem more likely to participate in these programs than SMEs operating in scaleintensive and supplier-dominated industries. Therefore, policy measures to increase SMEs' participation in these programs should specifically target the former types of SMEs. Second, it seems that the costs-of-participation barrier is hindering SMEs from participating in these programs. Lowering this cost barrier might stimulate SME participation in EU collaborative research programs, since the trade-off between the expected costs and benefits exerts a primary influence on the likelihood of SMEs participating in these programs (Gilmore et al. 2013). Subsidizing application costs could be considered as a potential policy measure in this respect as is proposed in the EU Horizon 2020 program (European Commission 2013). Another possible policy measure might be providing governmental guarantees for dedicated bank loans taken by SMEs, which has been taken up in the EU COSMO program 2014-20 (European Commission 2014b). Lowering the cost barrier might also be achieved by assigning a larger share of the subsidies paid to the participants in EU collaborative research projects to the participating SMEs (i.e. raising the benefits of cost sharing for SMEs). Third, many SMEs have no or limited experience with international collaboration (Gilmore et al. 2013). Therefore they should be provided with better information about the uncertainties and benefits of participating in EU collaborative research programs. Prior experience with international collaboration stimulates SMEs to participate in EU collaborative research programs, as it reduces the (possibly pessimistic) biases in their perceptions of the benefits and costs of participating in these programs and their uncertainties about the realization of those perceived benefits and costs.

However, before implementing the policy measures proposed above, their effectiveness should first be assessed in randomized policy experiments involving small numbers of SMEs. Furthermore, whether or not the stimulation of SME participation in EU collaborative research programs also results in more commercialization of research results produced remains an issue of concern.

\subsection{Limitations and further research}

A few limitations of this study are worth noting, and raise questions which could be the topic of further research. First, the results presented in this study should be regarded as tentative, as they are derived from a typical sample of Dutch R\&D-based SMEs that received tax reductions on actually performing $R \& D$. One possible effect might be that this tax reduction scheme decreases the need for R\&D-based SMEs to participate in EU programs. Another possible effect might be that this study included R\&D-based SMEs, which are more eager to find public funding of their $R \& D$ than other R\&D-based SMEs. As our sample did not include R\&D-based SMEs that did not receive these tax reductions, these contradictory effects remain to be investigated in further research. Moreover, the response rate to our survey was quite low and limited to the Netherlands, which places additional limitations on the generalizability of our findings. Nevertheless, our results make theoretical sense and do provide insights into the combined effects of incentives and barriers on the (non)participation of SMEs in EU research programs. Therefore, the tentative results should also be replicated in other countries with higher response rates.

Second, the results are not likely to suffer much from common method bias (Podsakoff et al. 2003) as the data on the dependent variable in this study were obtained from administrative sources and not from the respondents themselves. Accordingly, the risk of correlations between the dependent variable and the independent concepts and control variables induced by biases in the respondents' answers to the questionnaire is quite low. But whether the results also hold for all R\&D-based SMEs in the Netherlands and for R\&D-based SMEs in other EU countries is a subject for future research. Additionally, further research is necessary in order to assess whether the results obtained are typical for the EP and FP7-CP programs investigated together or also hold for the EP and FP7-CP programs individually. This could not be assessed in this study because the subsample of 50 responding SMEs participating in the EP and FP7-CP programs contains only seven SMEs from the EP program, which is too small for further statistical analyses. Furthermore, future research should also assess whether or not the results obtained also hold for other SME-oriented EU programs and other forms of international public-private collaborations of R\&Dbased SMEs.

Third, the incentives for, and barriers against, SME participation in the EP and FP7-CP programs apply especially to science-based SMEs. Additionally, the results show that specialized-supplier SMEs are also likely to participate in these research programs, but the derived incentives for, and barriers to, this participation do not seem to apply to this category of SMEs, as their specification hardly affects the industry effect of specialized-supplier SMEs. Further research into this subject is clearly needed to clarify the differences between these categories of firms.

Fourth, the effects of Pavitt's industry classification on the (non)participation of Dutch R\&D-based SMEs in the EP and FP7$\mathrm{CP}$ programs should be considered as a first step towards the assessment of such effects. Archibugi (2001) argues that Pavitt's industry classification based on the more extensive industry classifications used by (inter)national statistical offices, for example the SBI codes used by Dutch Statistics (see Appendix 2), ignores the variety of high- and low-tech firms contained in each industry class. 
This variety of R\&D-based firms within each industry class, and thus also within each Pavitt (1984) class, implies that the estimated industry effects on the (non)participation of R\&D-based SMEs in EU research programs may only hold for a small proportion of the firms contained in each class, most probably high-tech firms. Castellacci (2009) demonstrated that each Pavitt class should be subdivided into a subclass of (high-tech?) firms maintaining strong ties with external sources of innovation and a subclass of (low-tech?) firms maintaining weak ties with external sources of innovation. Kirner et al. (2009) compared the industry classifications of firms with their individual $R \& D$ intensities. They found that firms classified as high-tech, medium-high-tech, medium-low-tech and low-tech based on their industry classifications matched for about $50 \%$ with the same classifications derived from their individual R\&D intensities. This shows that future research is clearly needed in order to assess which types of firms contained in each Pavitt class are more and less likely to (non)participate in the EP and FP7-CP programs and their successors.

Finally, as EU collaborative research programs are primarily focused on initiating research collaborations and their expected results as a prerequisite for innovation development instead of on actual profitable innovation development, the question arises of how successful these programs are in contributing to the EU's goal of strengthening the competitive position of its economy in the world market (European Commission 2010). This question is also rooted in one of the results obtained: that the financial incentive of the trade-off made by SMEs between the expected benefits of cost sharing and the expected costs of participation affects the likelihood that SMEs will participate in EU research programs more strongly than the incentive of new knowledge production and innovation via knowledge sharing. This result raises the question of how focused and successful the participating SMEs are with respect to actual profitable innovation development, which is essential for realizing the EU's goal of strengthening the competitive position of its economy in the world market. Therefore, the quantities and qualities of actually developed profitable innovations by participants in EU collaborative research programs are important subjects for further research.

\section{Notes}

1. Previous research indicates that of a total of $40 \%$ of Dutch SMEs, which cooperate with other enterprises, only $8 \%$ cooperate on an international basis (van Essen and Bhansing 2009).

2. This tax reduction program for Dutch SMEs currently actively performing R\&D is called the WBSO scheme $<$ http://www. agentschapnl/programmas-regelingen/wbso-research-and-development-rd-tax-credit> accessed 12 Nov 2010.

3. These firms were identified in the EU CORDIS database and the registrations of the Dutch Ministry of Economic Affairs of their co-financing of EP projects and the (successful) support given by the Dutch Europese Gemeenschap Liason to SMEs interested in participating in FP7-CP projects and/or any other EU research projects.

4. If we had taken a matched sample of $10 \%$, we would have ended with only 48 SMEs in our sample participating in either the FP7$\mathrm{CP}$ program or the EP program or both. Given the expected low response rates to the survey, we anticipated ending with only five or six respondents in our response set. This is far too few for statistical testing of the hypotheses and drawing inferences. Therefore, we decided to take a $10 \%$ random sample from only the registered set of SMEs not participating in any EU program.

\section{References}

Adler, P. S. and Kwon, S. W. (2002) 'Social capital: Prospects for a new concept'. Academy of Management Review, 27: 17-40.

AgentschapNL (2012) Nederland in KP7 2011. The Hague: AgentschapNL.

Ahuja, G. (2000) 'Collaboration networks, structural holes, and innovation: A longitudinal study'. Administrative Science Quarterly, 45: 425-55.

Amit, R. and Schoemaker, P. J. H. (1993) 'Strategic assets and organizational rent'. Strategic Management Journal, 14: 33-46.

Archibugi, D. (2001) 'Pavitt's taxonomy sixteen years on: A review article'. Economics of Innovation and New Technology, 10: 415-25.

Audretsch, D. B. and Keilbach, M. (2007) 'The theory of knowledge spillover entrepreneurship'. Journal of Management Studies, 44: 1242-54.

— annual report on EU small and medium-sized enterprises'. The Hague: EIM Business and Policy Research.

Bach, L., Matt, M. and Wolff, S. (2014) 'How do firms perceive policy rationales behind the variety of instruments supporting collaborative R\&D? Lessons from the European Framework Programs'. Technovation, 34: 327-37.

Barajas, A. and Huergo, E. (2010) 'International R\&D cooperation within the EU framework programme: Empirical evidence for Spanish firms'. Economics of Innovation and New Technology, 19: 87-111.

— _ _ and Moreno, L. (2012) 'Measuring the economic impact of research joint ventures supported by the EU Framework Programme'. Journal of Technology Transfer, 37: 917-42.

Barney, J. (1991) 'Firm resources and sustained competitive advantage'. Journal of Management, 17: 99-120.

Bogliacino, F. and Pianta, M. (2010) 'Innovation and employment: A reinvestigation using revised Pavitt classes'. Research Policy, 39: 799-809.

Boschma, R. A. (2005) 'Proximity and innovation: A critical assessment'. Regional Studies, 39: 61-74.

Brouthers, K. D., Nakos, G. and Dimitratos, P. (2014) 'SME entrepreneurial orientation, international performance, and the moderating role of strategic alliances'. Entrepreneurship Theory and Practice, doi: 10.1111/etap. 12101.27p.

Burt, R. S. (2004) 'Structural holes and good ideas'. American Journal of Sociology, 110: 349-99.

Caloghirou, Y., Vonortas, N. S. and Ioannides, S. (eds) (2004) European Collaboration in Research and Development: Business Strategy and Public Policy. Northampton, MA: Edward Elgar.

Castellacci, F. (2009) 'The interactions between national systems and sectoral patterns of innovation: A cross-country analysis of Pavitt's taxonomy'. Journal of Evolutionary Economics, 19: 321-47.

Centraal Bureau voor de Statistiek (2010) 'SBI '93: Standaard Bedrijfsindeling 1993'<http://www.cbs.nl/nl-NL/menu/methoden/classificaties/overzicht/ sbi/sbi-1993/default.htm > accessed 12 Jul 2010.

Cohen, W. M. and Levinthal, D. A. (1990) 'Absorptive capacity: A new perspective on learning and innovation'. Administrative Science Quarterly, 35: $128-52$.

Cooke, P., Uranga, M. G. and Etxebarria, G. (1997) 'Regional innovation systems: Institutional and organisational dimensions'. Research Policy, 26: 475-91.

CORDIS (2007) 'The main objectives of FP7: Specific programmes' < http:// cordis.europa.eu/fp7/understand_en.html > accessed 12 Nov 2010.

Cumming, D. and MacIntosh, J. G. (2006) 'Crowding out private equity: Canadian evidence'. Journal of Business Venturing, 21: 569-609.

Das, T. K. and Teng, B. (2000) 'A resource-based theory of strategic alliances'. Journal of Management, 26: 31-61.

Eisenhardt, K. M. and Martin, J. A. (2000) 'Dynamic capabilities: What are they?'. Strategic Management Journal, 21: 1105-21.

EUREKA (2013) 'The Eurostars Program' <http://www.eurostars-eureka. eu/> accessed 29 Nov 2013.

European Commission (2007) 'FP7 in brief' <http://ec.europa.eu/research/ fp7/pdf/fp7-inbrief_en.pdf $>$ accessed 20 Oct 2009.

— (2009) 'SME definition' <http://ec.europa.eu/enterprise/policies/sme/ facts-figures-analysis/sme-definition/index_en.htm > accessed 20 Oct 2009 
— (2010) 'Europe 2020 Flagship Initiative Innovation Union' < http://ec. europa.eu/research/innovation-union/pdf/innovation-union-communication_en.pdf\#view $=$ fit\&pagemode $=$ none $>$ accessed 5 Jun 2011 .

- (2012) 'Eighth Progress Report on SMEs' participation in FP7' <http:// ec.europa.eu/research/sme-techweb/pdf $>$ accessed 29 Nov 2013.

— (2013) 'Horizon 2020' <http://ec.europa.eu/research/horizon2020/ index_en.cfm> Accessed 29 Nov 2013.

- (2014a) 'Competitiveness and Innovation Framework Program (CIP)' $<$ http://ec.europa.eu/cip> accessed 6 Jan 2015

- (2014b) 'Program for the Competitiveness of Enterprises and SMEs (COSME)' < http://ec.europa.eu/cip> accessed 6 Jan 2015.

Fifo Ost (2010) 'NACE revision 1.1: Statistical Classification of Economic Activities 2010' <http://www.fifoost.org/database/nace/nace-en_2002c. php $>$ accessed 20 Aug 2010.

Gilmore, A., Galbraith, B. and Mulvenna, M. (2013) 'Perceived barriers to participation in R\&D programs for SMEs within the European Union'. Technology Analysis and Strategic Management, 25: 329-39.

Gulati, R. (1995a) 'Does familiarity breed trust? The implications of repeated ties for contractual choice in alliances'. Academy of Management Journal, 39: 1245-64.

_ (1995b) 'Social structure and alliance formation patterns: A longitudinal analysis'. Administrative Science Quarterly, 40: 619-52.

Gupta, S. and Malhotra, N. (2013) 'Marketing innovation: A resource-based view of international and local firms'. Marketing Intelligence and Planning, 31: 111-26.

Hagedoorn, J., Link, A. N. and Vonortas, N. S. (2000) 'Research partnerships'. Research Policy, 29: 567-86.

Harrison, J. S., Hitt, M. A., Hoskisson, R. E. and Ireland, R. D. (1991) 'Synergies and post-acquisition performance: Differences versus similarities in resource allocations'. Journal of Management, 17: 173-90.

— _ — _ - and Ireland, R. D. (2001) 'Resource complementarity in business combinations: Extending the logic to organizational alliances'. Journal of Management, 27: 679-90.

Hennart, J. F. and Zeng, M. (2002) 'Cross-cultural differences and joint venture longevity'. Journal of International Business Studies, 33: 699-716.

Hofstede, G., Neuijen, B., Ohavy, D. and Sander, G. (1990) 'Measuring organizational culture: a qualitative and quantitative study across twenty cases'. Administrative Science Quarterly, 35: 286-316.

Jöreskog, K. J. and Sörbom, D. (1993) LISREL ${ }^{\circledR}$ 8: User Reference Guide. Chicago, IL: SSI.

Keogh, W. and Evans, G. (1999) 'Strategies for growth and the barriers faced by new technology-based SMEs'. Journal of Small Business and Enterprise Development, 5: 337-50.

Kirner, E., Kinkel, S. and Jaeger, A. (2009) 'Innovation paths and the innovative performance of low-technology fims: An empirical assessment of German industry'. Research Policy, 38: 447-58.

Knight, G. A. (2001) 'Entrepreneurship and strategy in the international SME'. Journal of International Management, 7: 155-71.

Kogut, B. (1988) 'Joint ventures: Theoretical and empirical perspectives'. Strategic Management Journal, 9: 319-32.

Lloyd-Reason, L. and Mughan, T. (2008) 'Removing barriers to SME access to international markets: OECD-APEC global study'. USASBE 2008 Proceedings.

Luukkonen, T. (2002) 'Technology and market orientation in company participation in the EU framework programme'. Research Policy, 31: 599610.

Mahoney, J. T. and Pandian, J. R. (1992) 'The resource-based view within the conversation of strategic management'. Strategic Management Journal, 13: $363-80$.

Muijrers, F. and Faber, J. (2012) International Alliance Formation: An Escape from Domestic Stagnation. Saarbrücken, Germany: Lambert Academic.

Murray, J. Y., Kotabe, M. and Nan Zhou, J. (2005) 'Strategic alliance-based sourcing and market performance: Evidence from foreign firms operating in China'. Journal of International Business Studies, 36: 187-208.

Narula, R. (2004) 'R\&D collaboration by SMEs: New opportunities and limitations in the face of globalisation'. Technovation, 24: 153-61.
— and Hagedoorn, J. (1999) 'Innovating through strategic alliances: Moving towards international partnerships and contractual agreements'. Technovation, 19: 283-94.

Newbert, S., (2007) 'Empirical research on the resource-based view of the firm: An assessment and suggestions for future research'. Strategic. Management Journal, 28: 121-46.

Nieto, M. J. and Santamaria, L. (2010) 'Technological collaboration: Bridging the innovation gap between small and large firms'. Journal of Small Business Management, 48: 44-69.

Nooteboom, B., Van Haverbeke, W., Duysters, G., Gilsing, V. and van den Oord, A. (2007) 'Optimal cognitive distance and absorptive capacity'. Research Policy, 36: 1016-34.

North, D. C. (1990) Institutions, Institutional Change and Economic Performance. Cambridge, UK: CUP.

O'Brien, R. M. (2007) 'A caution regarding rules of thumb for variance inflation factors'. Quality and Quantity, 41: 673-90.

Olsson, U. (1979) 'Maximum likelihood estimation of the polychoric correlation coefficient'. Psychometrika, 44: 443-60.

_ D Drasgow, F. and Dorans, N. J. (1982) 'The polyserial correlation coefficient'. Psychometrika, 47: 337-47.

Pavitt, K. (1984) 'Sectoral patterns of technical change: Towards a taxonomy and a theory'. Research Policy, 13: 343-73.

Penrose, E. T. (1959) The Theory of the Growth of the Firm. New York: Wiley.

Podsakoff, P. M., MacKenzie, S. B., Lee, J. and Podsakoff, N. P. (2003) 'Common method biases in behavioral research: A critical review of the literature and recommended remedies'. Journal of Applied Psychology, 88: 879-903.

Ponds, R., Van Oort, F. and Frenken, K. (2007) 'The geographical and institutional proximity of research collaboration'. Papers in Regional Science, 86: $423-43$.

Powell, W. W., Koput, K. W. and Smith-Doerr, L. (1996) 'Interorganizational collaboration and the locus of innovation: Networks of learning in biotechnology'. Administrative Science Quarterly, 41: 116-45.

Protogerou, A., Caloghirou, Y. and Siokas, E. (2010) 'Policy-driven collaborative research networks in Europe'. Economics of Innovation and New Technology, 19: 349-72.

— _ — and — (2013) 'Twenty-five years of science-industry collaboration: The emergence and evolution of policy-driven research networks across Europe'. Journal of Technology Transfer, 38: 873-95.

Riley, M. W. (1963) Sociological Research - I: A Case Approach. New York: Harcourt Brace Jovanovich.

Ruef, M., Aldrich, H. E. and Carter, N. M. (2003) 'The structure of founding teams: Homophily, strong ties, and isolation among US entrepreneurs'. American Sociological Review, 68: 195-222.

Schein, E. (1990) 'Organizational culture'. American Psychologist, 45: 109-19.

Schneider, C. and Veugelers, R. (2010) 'On young highly innovative companies: Why they matter and how (not) to policy support them'. Industrial and Corporate Change, 19: 969-1007.

Scott, W. R. (1995) Institutions and Organizations. Foundations for Organizational Science. Thousand Oaks, CA: Sage.

Senternovem (2009) 'Nederland in KP7 2008'<http://www.rvo.nl/subsidiesregelingen/kp7-publicaties $>$ accessed 12 Nov 2012.

Sirmon, D. G. and Lane, P. J. (2004) 'A model of cultural differences and international alliance performance'. Journal of International Business Studies, 35: 306-19.

Spencer, J. W. (2003) 'Firms' knowledge-sharing strategies in the global innovation system: Empirical evidence from the flat panel display industry'. Strategic Management Journal, 24: 217-33.

Stinchcombe, A. (1965) 'Social structure and organizations' in Handbook of Organizations, J. G. March (ed.), pp. 142-93. Chicago, IL: Rand McNally.

Tabachnick, B. G. and Fidell, L. S. (2007) Using Multivariate Statistics. Boston, MA: Allyn and Bacon.

Technopolis (2009) Impact Europese kaderprogramma's in Nederland. The Hague: AgentschapNL. 
Teece, D. J. (1986) 'Profiting from technological innovation: Implications for integration, collaboration, licensing and public policy'. Research Policy, 15: 285-305.

Tidd, J. and Bessant, J. (2013) Managing Innovation: Integrating Technological, Market and Organizational Change. Chichester, UK: Wiley.

Van Essen, C. and Bhansing, P. (2009) Internationale samenwerking door het Nederlandse MKB. Zoetermeer, the Netherlands: EIM.

van Praag, C. M. and Versloot, P. H. (2007) 'What is the value of entrepreneurship? A review of recent research'. Small Business Economics, 29: 351-82.

Van Rijnsoever, F. J., Vander Berg, J., Koch, J. and Hekkert, M. P. (2015) 'Smart innovation policy: How network position and project position affect the diversity of an emerging technology'. Research Policy, 44: 1094-107.
Van Rijnsoever, Welle, L. and Bakker, S. (2014) 'Credibility and legitimacy in policy-driven innovation networks: Resource dependencies and expectations in Dutch electric vehicle subsidies'. Journal of Technology Transfer, 39: 635-61.

Wernerfelt, B. (1984) 'The resource-based view of the firm'. Strategic Management Journal, 5: 171-80.

Williamson, O. E. (1981) 'The economics of organization: The transaction cost approach'. American Journal of Sociology, 87: 548-77.

Zahra, S. A., Ucbasaran, D. and Newey, L. R. (2009) 'Social knowledge and SMEs' innovative gains from internationalization'. European Management Review, 6: 81-93.

\section{Appendixes}

\section{Appendix 1. Questionnaire web survey}

How many years does your firm exist?

\section{$\square$ Years}

To which industry category does your firm belong?

How many people did your firm employ last year?

$\square 0$ - 10 employees $\square 11-50$ employees $\square 51-250$ employees

Which activities did your firm perform during the last 3 years? (multiple answers are possible)

$\square$ Imports $\quad \square$ Exports $\square$ International collaboration

$\square$ Other international activities $\square$ None of them

Why does/would your firm participate in the Cooperation subprogram of the $7^{\text {th }}$ Framework Program or the Eurostars Program of the EU?

$\begin{array}{lllll}\text { Not } & \text { Less } & \text { Moderate } & \text { Rather } & \text { Very } \\ \text { important } & \text { important } & \text { important } & \text { important } & \text { important } \\ \square & \square & \square & \square & \square \\ \square & \square & \square & \square & \square \\ \square & \square & \square & \square & \square \\ \square & \square & \square & \square \\ \square & \square & \square & \square & \square \\ \square & \square & \square & \square & \square \\ \square & \square & \square & \square & \square\end{array}$

Why does/would your firm not participate in the Cooperation subprogram of the $7^{\text {th }}$ Framework Program or the Eurostars Program of the EU? $\underline{\text { Strategic barriers }}$

- Subjects of the programs do not fit to the daily practices of the firm.

- Subjects of the programs are too theoretical and too little applicable within the firm.

Barriers related to the firm's resources

- Time required.

- Availability of personnel.

- Availability of finances.

Cultural and relational barriers

- Difficulties with finding suitable foreign partners.

- Not speaking the language spoken by potential foreign partners.

- Difference in habits and behavior with potential foreign partners.

Barriers related to the application procedures

- Complexity of the application procedures.

- Time consumption of the application procedures.

$\begin{array}{lllll}\text { Not } & \text { Less } & \text { Moderate } & \text { Rather } & \text { Very } \\ \text { important } & \text { important } & \text { important } & \text { important } & \text { important } \\ \square & \square & \square & \square & \square \\ \square & \square & \square & \square & \square \\ \square & \square & \square & \square & \square \\ \square & \square & \square & \square & \square \\ \square & \square & \square & \square & \square \\ \square & \square & \square & \square & \square \\ \square & \square & \square & \square & \square \\ \square & \square & \square & \square & \square \\ \square & \square & \square & \square & \square \\ \square & \square & \square & \square & \square\end{array}$


Appendix 2. Pavitt's classification of industry types

\begin{tabular}{|c|c|c|c|}
\hline & Industry & Pavitt & $\mathrm{N}$ \\
\hline 1 & Agriculture, forestry and fishing & Supplier-dominated & 12 \\
\hline 2 & Mining and quarrying & Scale-intensive & 0 \\
\hline 3 & Manufacture of food products, beverages and tobacco & Supplier-dominated & 3 \\
\hline 4 & Manufacture of textiles and leather (products) & Supplier-dominated & 3 \\
\hline 5 & Manufacture of pulp, paper and paper products & Scale-intensive & 1 \\
\hline 6 & Publishing, printing and reproduction of recorded media & Scale-intensive & 0 \\
\hline 7 & Manufacture of coke, refined petroleum products and nuclear fuel & Scale-intensive & 0 \\
\hline 8 & Manufacture of chemicals and chemical products & Science-based & 21 \\
\hline 9 & Manufacture of rubber and plastic products & Scale-intensive & 11 \\
\hline 10 & Manufacture of basic metals and fabricated metal products & Scale-intensive & 21 \\
\hline 11 & 'Manufacture of machinery and equipment n.e.c. & Specialized-suppliers & 18 \\
\hline 12 & Manufacture of electrical and optical equipment & Science-based & 20 \\
\hline 13 & Manufacture of transport equipment & Scale-intensive & 4 \\
\hline 14 & Other industries & Supplier-dominated & 7 \\
\hline 15 & Electricity, gas and water supply & Supplier-dominated & 6 \\
\hline 16 & Construction & Supplier-dominated & 4 \\
\hline 17 & Wholesale, repair and hospitality & Supplier-dominated & 3 \\
\hline 18 & Transport, storage and communication & Supplier-dominated & 2 \\
\hline 19 & Financial intermediation & Scale-intensive & 1 \\
\hline 20 & Computer and related activities & Science-based & 25 \\
\hline 21 & Research and development & Science-based & 30 \\
\hline 22 & Legal and economic consultancy & Specialized-suppliers & 1 \\
\hline 23 & Architectural and engineering activities and related technical consultancy & Specialized-suppliers & 8 \\
\hline 24 & Renting and other business activities & Specialized-suppliers & 1 \\
\hline 25 & Governmental & Supplier-dominated & 0 \\
\hline 26 & Health and social work & Supplier-dominated & 10 \\
\hline 27 & Environmental services & Supplier-dominated & 3 \\
\hline 28 & Other services & Supplier-dominated & 32 \\
\hline
\end{tabular}

Based on Bogliacino and Pianta (2010)

Appendix 3. Descriptive statistics and correlations of observed variables $(N=247)$

\begin{tabular}{|c|c|c|c|c|c|c|c|c|}
\hline & Mean & Stand. dev. & $(1)$ & $(2)$ & (3) & (4) & $(5)$ & (6) \\
\hline Participation int. collaboration (1) & 0.20 & 0.403 & 1.000 & & & & & \\
\hline Imports $(2)$ & 0.49 & 0.501 & -0.054 & 1.000 & & & & \\
\hline Exports (3) & 0.65 & 0.479 & -0.015 & 0.818 & 1.000 & & & \\
\hline Prior int. collaboration (4) & 0.70 & 0.459 & 0.644 & 0.211 & 0.411 & 1.000 & & \\
\hline Alternative int. contacts (5) & 0.38 & 0.487 & 0.218 & 0.105 & 0.205 & 0.378 & 1.000 & \\
\hline Age (6) & 15.91 & 13.258 & -0.158 & 0.230 & 0.133 & -0.187 & -0.130 & 1.000 \\
\hline Size (7) & 1.67 & 0.723 & -0.034 & 0.262 & 0.247 & 0.124 & 0.024 & 0.504 \\
\hline Science-based (8) & 0.39 & 0.488 & 0.273 & -0.107 & -0.005 & 0.146 & -0.070 & -0.339 \\
\hline Scale-intensive (9) & 0.11 & 0.313 & -0.251 & 0.315 & 0.261 & -0.170 & 0.068 & 0.311 \\
\hline Specialized supplier (10) & 0.15 & 0.362 & 0.111 & 0.370 & 0.433 & 0.207 & 0.204 & 0.083 \\
\hline Supplier-dominated (11) & 0.35 & 0.476 & -0.210 & -0.290 & -0.343 & -0.110 & -0.068 & 0.079 \\
\hline Access compl. knowledge (12) & 4.03 & 0.881 & 0.138 & -0.055 & 0.070 & 0.169 & 0.034 & -0.123 \\
\hline Extending org. network (13) & 4.06 & 0.828 & 0.296 & -0.016 & -0.007 & 0.212 & 0.119 & -0.163 \\
\hline Access new markets (14) & 4.00 & 0.889 & 0.072 & -0.018 & 0.116 & 0.179 & 0.101 & -0.042 \\
\hline Cost sharing R\&D (15) & 4.32 & 0.800 & 0.273 & -0.101 & -0.011 & 0.067 & 0.192 & -0.241 \\
\hline Cost sharing new prod. dev. (16) & 4.34 & 0.807 & 0.167 & -0.127 & -0.039 & 0.048 & 0.202 & -0.191 \\
\hline Knowledge sharing (17) & 2.76 & 1.066 & -0.038 & 0.181 & 0.178 & 0.030 & -0.131 & 0.166 \\
\hline IPR sharing (18) & 3.22 & 1.146 & 0.100 & -0.070 & 0.036 & -0.012 & -0.104 & 0.078 \\
\hline Time for participation (19) & 3.66 & 0.988 & -0.159 & 0.014 & 0.055 & 0.123 & -0.084 & -0.017 \\
\hline Personnel for participation (20) & 3.57 & 0.955 & -0.066 & 0.013 & 0.133 & 0.139 & -0.072 & 0.073 \\
\hline Finances for participation (21) & 3.80 & 0.961 & 0.001 & -0.121 & -0.199 & -0.042 & -0.072 & 0.009 \\
\hline Complexity of application (22) & 3.82 & 0.873 & 0.009 & 0.023 & 0.025 & 0.053 & 0.005 & -0.019 \\
\hline Duration of application (23) & 3.94 & 0.883 & 0.028 & -0.089 & -0.077 & 0.064 & 0.089 & -0.051 \\
\hline Difference in subjects (24) & 3.48 & 0.966 & 0.143 & -0.056 & -0.038 & 0.053 & -0.076 & 0.021 \\
\hline Difference in theor. level (25) & 3.28 & 1.085 & -0.215 & 0.127 & 0.009 & -0.056 & -0.049 & 0.115 \\
\hline
\end{tabular}


Appendix 3. (continued)

\begin{tabular}{|c|c|c|c|c|c|c|c|c|}
\hline & Mean & Stand. dev. & (1) & (2) & (3) & (4) & (5) & (6) \\
\hline Difficulties with partnering (26) & 3.24 & 0.954 & -0.263 & 0.013 & -0.185 & -0.364 & -0.256 & 0.011 \\
\hline Differences in language (27) & 1.96 & 0.958 & -0.274 & -0.014 & 0.149 & -0.220 & -0.139 & 0.195 \\
\hline Differences in habits (28) & 2.03 & 0.982 & -0.168 & -0.033 & 0.015 & -0.188 & -0.164 & 0.158 \\
\hline
\end{tabular}

(7) (8)

(9)

(10)

(11)

(12)

Size (7)

Science-based (8)

Scale-intensive (9)

Specialized supplier (10)

Supplier-dominated (11)

Access compl. knowledge (12)

Extending org. network (13)

Access new markets (14)

Cost sharing R\&D (15)

Cost sharing new prod. dev. (16)

Knowledge sharing (17)

IPR sharing (18)

Time for participation (19)

Personnel for participation (20)

Finances for participation (21)

Complexity of application (22)

Duration of application (23)

Difference in subjects (24)

Difference in theor. level (25)

Difficulties with partnering (26)

Differences in language (27)

Differences in habits (28)
1.000

$-0.103$

0.272

0.135

$-0.134$

$-0.006$

$-0.089$

$-0.003$

$-0.243$

$-0.187$

0.162

$-0.009$

0.002

0.100

$-0.247$

$-0.069$

$-0.030$

0.160

0.189

0.006

0.088

0.042

(13)

$$
\begin{array}{r}
1.000 \\
-0.965 \\
-0.954 \\
-0.991 \\
0.097 \\
0.155 \\
-0.086 \\
0.065 \\
0.074 \\
0.004 \\
-0.008 \\
-0.036 \\
-0.055 \\
-0.164 \\
0.052 \\
0.054 \\
0.064 \\
-0.129 \\
-0.025 \\
-0.122 \\
-0.048
\end{array}
$$

(14)

1.000

$-0.891$

$-0.958$

$-0.042$

$-0.035$

0.041

0.121

0.082

0.290

0.172

0.080

0.189

$-0.060$

0.001

$-0.055$

0.122

0.208

0.100

0.239

0.173
1.000

$\begin{array}{ll}-0.946 & 1.000\end{array}$

$-0.032$

$-0.029$

0.082

$-0.217$

$-0.288$

$-0.127$

$-0.142$

$-0.120$

$-0.108$

0.047

0.000

$-0.032$

0.003

$-0.034$

$-0.028$

$-0.206$

$-0.284$

-0.057
-0.112
0.042
-0.013
0.040
-0.112
-0.021
0.051
-0.009
0.180
-0.052
-0.004
-0.141
0.025
-0.025
0.068
0.073
(15)

(16)

(17)

1.000

0.535

0.409

0.386

0.253

0.035

0.069

0.129

0.153

0.227

0.001

0.114

0.052

0.003

$-0.054$

$-0.126$

$-0.145$

(18)

Extending org. network (13)

Access new markets (14)

\subsection{0}

Cost sharing R\&D (15)

Cost sharing new prod. dev. (16)

Knowledge sharing (17)

IPR sharing (18)

Time for participation (19)

Personnel for participation (20)

Finances for participation (21)

Complexity of application (22)

Duration of application (23)

Difference in subjects (24)

Difference in theor. level (25)

Difficulties with partnering (26)

Differences in language (27)

Differences in habits (28)

0.263

0.167

\subsection{4}

0.069

$-0.044$

$-0.030$

0.110

0.094

0.120

$-0.103$

$-0.228$

$-0.177$

(19)

1.000

Time for participation (19)

Personnel for participation (20)

Finances for participation (21)

Complexity of application (22)

Duration of application (23)

Difference in subjects (24)

Difference in theor. level (25)

Difficulties with partnering (26)

Differences in language (27)

Differences in habits (28)

$\begin{array}{lll}1.000 & & \\ 0.750 & 1.000 & \\ 0.366 & 0.452 & 1.000 \\ 0.361 & 0.190 & 0.107 \\ 0.397 & 0.202 & 0.143 \\ 0.164 & 0.220 & 0.045 \\ 0.201 & 0.203 & 0.127 \\ 0.135 & 0.071 & 0.121 \\ 0.063 & 0.081 & 0.033 \\ 0.032 & 0.124 & 0.127\end{array}$

0.672

0.100

0.083

1.000

0.150

0.102

0.089

0.007

0.024

0.187

0.045

0.030

0.030

0.169

$-0.048$

0.033

$-0.029$

(20)

(26)

$(25)$

1.000

0.090

0.072

0.077
0.226

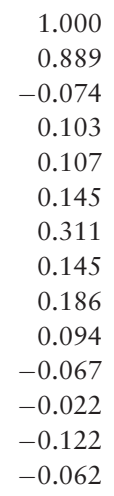

(21)

0.107

143
.045

127

033
127

(27)

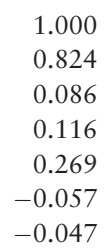

1.000

$-0.079$

0.143

0.181

0.190

0.301

0.132

0.157

0.129

0.115

$-0.001$

$-0.053$

$-0.046$

(22)

1.000

0.702

0.079

0.134

$-0.029$

$-0.105$

$-0.127$

0.172

0.261

0.087

0.097

0.070

1.000

0.205

0.247

0.236

$-0.117$

$-0.058$

0.162

0.275

$-0.056$

0.053

0.065

(24)

Difference in theor. level (25)

Difficulties with partnering (26)

Differences in habits (28)
1.000

0.229

0.185
1.000

0.818

1.000
0.122
0.081
0.125
-0.054
-0.036

1.000

0.475

$-0.071$

0.047

$-0.030$ 